\title{
Estudo do anticorpo monoclonal 56G anti-Streptococcus mutans: papel na prevenção e colonização da superfície de corpos de prova confeccionados com resina composta
}

\section{Evaluation of a 566 Anti - Streptococcus mutans monoclonal antibody: role in the prevention of colonization on surface of composite resin}

\section{Fabio José Condino FUJARRA}

Mestrando - Departamento Neurologia - Hospital Clínicas - Faculdade de Medicina - Universidade de São Paulo - USP - São Paulo - SP - Brasil

\section{Antonio Carlos Victor CANETTIERI}

Mestre em Biopatologia Bucal - Faculdade de Odontologia de São José dos Campos - Universidade Estadual Paulista - UNESP - São José dos Campos - SP - Brasil

\section{Fujiko Yamasiro KRETCHETOFF}

Mestre em Biopatologia Bucal - Faculdade de Odontologia de São José dos Campos - Universidade Estadual Paulista - UNESP - São José dos Campos - SP - Brasil

\section{Daniella MOREIRA}

Doutora em Biopatologia Bucal - Faculdade de Odontologia de São José dos Campos-- Universidade Estadual Paulista - UNESP - São José dos Campos - SP - Brasil

\section{Carmelinda Schmidt UNTERKIRCHER}

Professora Adjunta - Departamento de Biociências e Diagnóstico Bucal - Faculdade de Odontologia de São José dos Campos - Universidade Estadual Paulista - UNESP - São José dos Campos - SP - Brasil

\section{Resumo}

\begin{abstract}
Neste trabalho foi realizada uma análise, in vitro, da capacidade do anticorpo monoclonal (Acmo) $56 \mathrm{G}$ anti-Streptococcus mutans de impedir ou interferir na aderência e colonização de S.mutans (cepa GS5) à superfície de corpos de prova confeccionados com Resina Composta Híbrida TPH (Dentsply). Vinte corpos de prova foram preparados, desinfetados com gluconato de clorexidina ou esterilizados por radiação gama com cobalto 60 e incubados em tubos de ensaio contendo meio sacarosado e um inóculo de S. mutans. Metade dos corpos de prova constituiu o grupo tratado e, por isso, recebeu uma alíquota do Acmo; a outra metade destinou-se ao grupo controle. As películas bacterianas aderidas sobre as pastilhas de resina dos grupos tratado e controle foram quantificadas e comparadas através da dosagem de carboidratos e proteínas presentes nas mesmas, além da determinação do número de UFC/ml. Verificou-se que não havia diferença entre a desinfecção com clorexidina e a esterilização por radiação gama, e que o biofilme bacteriano formado na presença do Acmo não diferia daquele formado na sua ausência, tanto nas dosagens de carboidratos e proteínas $(p=0,577$ e $p=0,705$, respectivamente) quanto na microbiológica $(p=0,488)$. Conclui-se que o Acmo $56 \mathrm{G}$ não foi efetivo na prevenção da colonização da superfície dos corpos de prova confeccionados em resina pelo $S$. mutans.
\end{abstract}

\section{UNITERMOS}

Streptococcus mutans; anticorpos monoclonais; resinas compostas. 
ESTUDO DO ANTICORPO MONOCLONAL 56G ANTI-STREPTOCOCCUS MUTANS: PAPEL NA PREVENÇÃO E COLONIZAÇÃO DA SUPERFÍCIE DE CORPOS DE PROVA CONFECCIONADOS COM RESINA COMPOSTA.

\section{INTRODUÇÃo}

Dentre os estreptococos, os do grupo mutans merecem atenção especial no que se refere à cárie dentária, pois são pioneiros na colonização da superfície dos dentes, desempenhando papel decisivo na formação da placa dentária. A denominação $S$. mutans é reservada principalmente para as cepas dos sorotipos $c, e, f$, encontradas em hospedeiros humanos ${ }^{9}$. Os antígenos dos sorotipos são polissacarídeos da parede celular, compostos de ramnose, glicose e galactose. Além dos polissacarídeos, uma proteína importante foi identificada, o antígeno I/II, que atuaria como uma adesina, permitindo a ligação inicial do $S$. mutans à película adquirida, que recobre a superfície dentária, sendo, pois, considerada um fator de virulência responsável pela patogenicidade desse microrganismo $\mathbf{1 , 3 , 8 , 9}^{\mathbf{3}, \mathbf{9}}$.

Dada a prevalência da doença cárie, considerada um dos maiores problemas de saúde bucal em países em desenvolvimento, e considerando a participação do $S$. mutans na etiologia dessa doença, o estudo de um anticorpo monoclonal direcionado contra uma adesina do $S$. mutans contribuiria para o desenvolvimento de um método de imunoprofilaxia passiva, prevenindo a instalação da cárie dentária ${ }^{4,6,11}$.

O presente trabalho teve por objetivo avaliar a capacidade bloqueadora do Acmo 56G, anti-S. mutans, na aderência e colonização do $\mathrm{S}$. mutans à superfície de um material restaurador de uso odontológico, a resina composta.

\section{Materials e mÉtodos}

\section{O Streptococcus mutans}

A cepa GS5 foi a que demonstrou no ELISA maior reatividade com o anticorpo monoclonal 56G sendo, por isso, selecionada para os experimentos ${ }^{2,5}$.

\section{Os corpos de prova}

A resina composta híbrida TPH (Dentsply) cor $\mathrm{A}_{3}$ foi utilizada para confecção dos corpos de prova. Uma matriz de acrílico bipartida especialmente confeccionada possibilitou a produção de pastilhas de resina composta de $5 \mathrm{~mm}$ de diâmetro por $2 \mathrm{~mm}$ de espessura (Figura 1).

Antes de empregá-los nos experimentos, os corpos de prova receberam tratamento para sua descontaminação. Foram empregados dois métodos: esterilização por radiação gama com cobalto 60 e desinfecção com clorexidina $0,12 \%$ durante 15 minutos.

\section{Comparação entre os métodos de descontami- nação da resina composta}

Nesse experimento empregou-se 28 corpos de prova, divididos em 4 grupos (2 tratados e 2 controles). Os grupos tratados (placa bacteriana formada na presença do Acmo 56G) eram constituídos por 10 corpos de prova esterilizados e por 10 corpos de prova desinfetados. Os grupos controles (placa bacteriana formada na ausência do Acmo 56G) eram constituídos por 4 corpos de prova esterilizados e por 4 corpos de prova desinfetados.
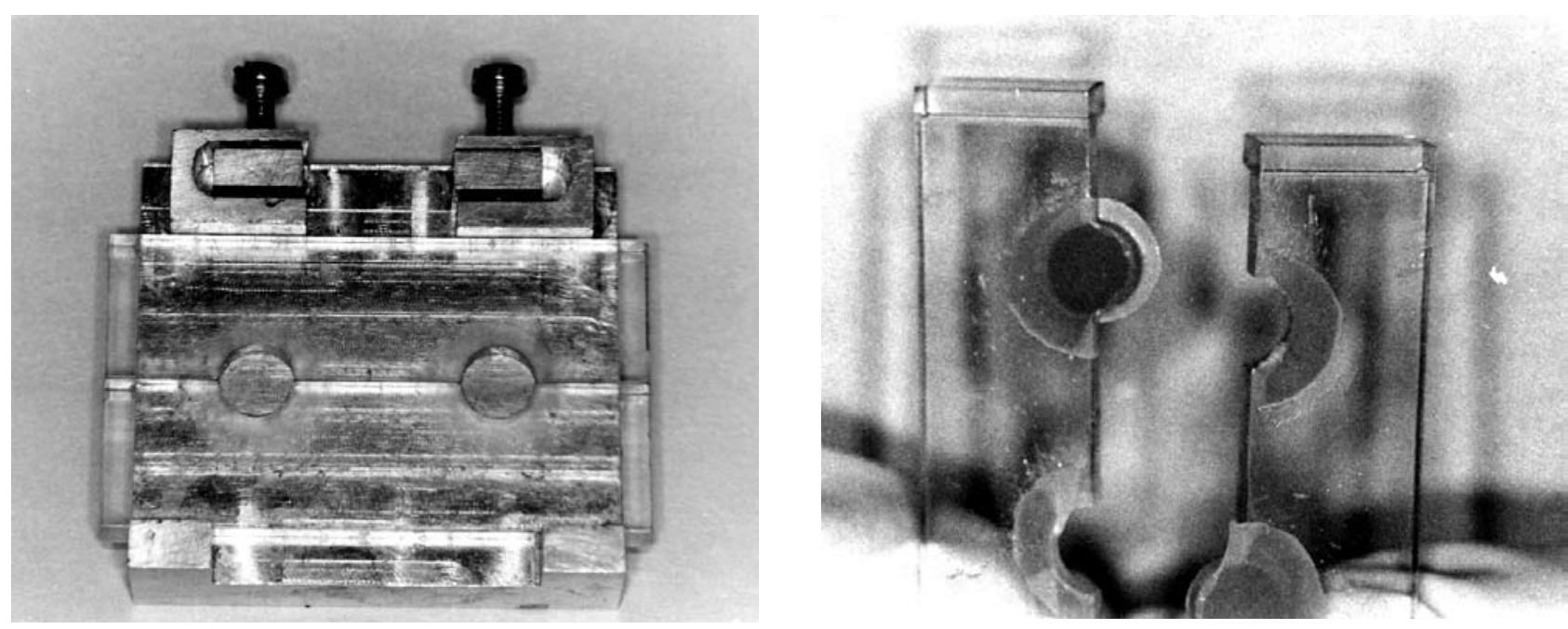

FIGURA 1 - Detalhe da confecção dos corpos de prova. 1A - Matriz bipartida de acrílico empregada no experimento. 1B - Corpos de prova sendo removidos da matriz após acomodação e fotopolimerização da resina composta. 


\section{Estudo da formação de placa bacteriana in vitro sobre resina composta}

No intuito de averiguar o papel do Acmo $56 \mathrm{G}$ na prevenção da colonização da superfície dos corpos de prova, outro experimento foi elaborado. Neste ensaio, foram empregadas vinte pastilhas de resina, que após desinfecção com gluconato de clorexidina $0,12 \%$, foram divididas em 2 grupos (tratado e controle), compostos por 10 elementos cada um.

\section{Análise bioquímica dos biofilmes bacterianos}

Todos os corpos de prova foram inseridos em tubos de ensaio contendo $1 \mathrm{ml}$ de meio sacarosado ${ }^{2}$. Nos tubos correspondentes ao grupo tratado foram adicionados $100 \mu \mathrm{g} / \mathrm{ml}$ de anticorpo monoclonal 56G. Todos os tubos foram incubados a $37^{\circ} \mathrm{C}$ em condições de microaerobiose durante 24 horas.

Após o período de incubação, as películas bacterianas aderidas sobre as pastilhas de resina dos grupos tratado e controle foram quantificadas e comparadas através da dosagem de carboidratos e proteínas presentes nas mesmas, além da determinação do número de unidades formadoras de colônia por mililitro(UFC/ $\mathrm{ml})$.

$\mathrm{Na}$ dosagem bioquímica, os corpos de prova foram retirados do meio sacarosado e lavados delicadamente em solução salina a $0,85 \%$ esterilizada, visando à remoção de resíduos do meio de cultura. A seguir foram transferidos para tubos de ensaio contendo $1 \mathrm{ml}$ da mesma solução e, então, vigorosamente agitados em aparelho "vórtex" por 1 minuto. Tal procedimento teve por finalidade a desagregação do biofilme bacteriano aderido sobre as pastilhas de resina, colocando-o em suspensão na solução salina. A partir desta suspensão, duas alíquotas foram retiradas e analisadas por métodos colorimétricos, através das dosagens bioquímicas. $\mathrm{O}$ reagente revelador de proteínas foi preparado com Coomassie Brilliant Blue G -CBB G250-(Sigma), etanol $95 \%$ e ácido fosfórico concentrado ${ }^{2}$. Já o reagente para evidenciação de carboidratos foi a Antrona, empregada segundo metodologia proposta por Pons ${ }^{10}(1981)$. As leituras foram realizadas num leitor ELISA (modelo 3550, BIO RAD), a um comprimento de onda de $590 \mathrm{~nm}$. A fim de correlacionar a densidade óptica das amostras com as respectivas concentrações protéicas e de carboidratos, uma curva padrão de albumina e outra de manose foram confeccionadas empregando-se concentrações crescentes dessas substâncias.

\section{Análise microbiológica dos biofilmes}

Outro recurso para compararmos a quantidade de biofilme bacteriano aderido sobre os corpos de prova foi a contagem de UFC/ml. O biofilme bacteriano em suspensão foi diluído nas proporções 1:100, 1:1000 e

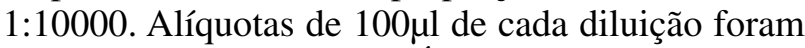
semeadas em duplicata em Ágar Mitis Salivarius (Difco) incubadas em estufa a $37^{\circ} \mathrm{C}$ por 48 horas.

\section{Efeito bactericida do Acmo 56G sobre $S$.} mutans

Para determinar se o anticorpo monoclonal 56G apresentava algum efeito bactericida, comparamos sua atividade com a da penicilina, que é um antibiótico de ação comprovada contra os $S$. mutans. Neste propósito, discos de papel impregnados com o Acmo ou penicilina foram aplicados sobre Ágar Mittis Salivarius previamente semeado com a cepa GS5.

\section{Análise estatística}

Os valores obtidos com as dosagens bioquímicas e microbiológica dos grupos tratado e controle foram comparados estatisticamente, empregando-se o Teste Mann-Whitney para as dosagens de carboidratos, e o Teste T (Student) para as dosagens protéicas e contagens de UFC/ml.

\section{Resultados}

Verificou-se que não havia diferença estatisticamente significante entre os grupos controle e tratado, tanto nas dosagens de carboidratos e proteínas $(\mathrm{p}=0.577$ e $p=0.705$, respectivamente), quanto na microbiológica $(\mathrm{p}=0.488)$.

Não houve diferença nas dosagens protéicas das placas (grupos controle e tratado) formadas sobre a resina composta esterilizada por radiação gama ou desinfetada por gluconato de clorexidina $0,12 \%$.

Nenhum efeito bactericida do Acmo 56G foi observado (Figura 2), uma vez que este não foi capaz de produzir halos de inibição em Agar Mitis Salivarius, enquanto que os discos de penicilina produziram halos de até $3 \mathrm{~cm}$ de diâmetro. 


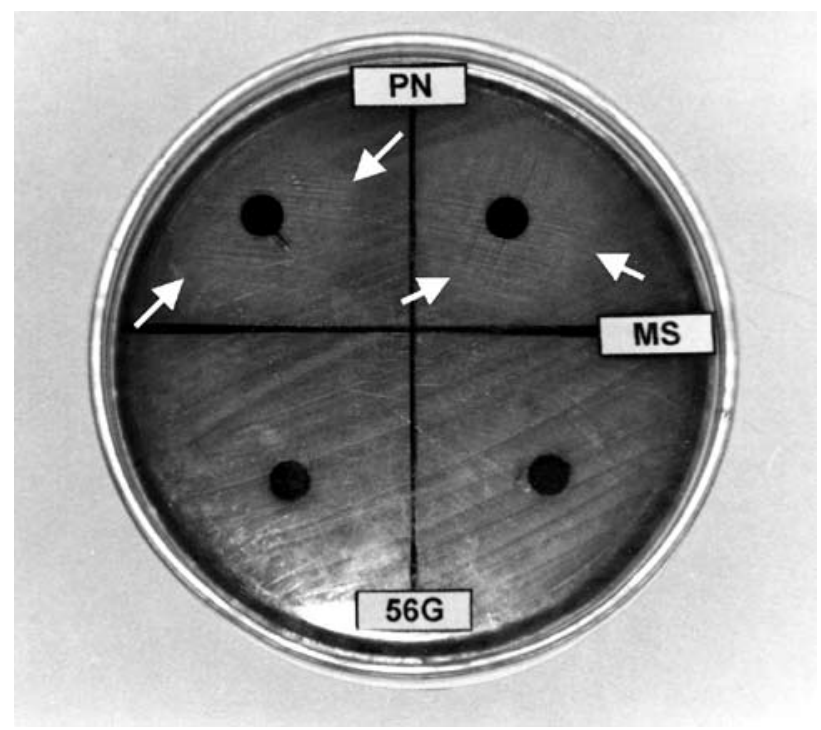

FIGURA 2 - Cultura de S. mutans em Ágar Mitis Salivarius (MS): as setas indicam os halos inibitórios produzidos pela penicilina (PN); nos quadrantes inferiores, nota-se que o Acmo $56 \mathrm{G}$ não apresenta efeito bactericida.

\section{Dıscussão}

As bactérias possuem superfícies com carga negativa e ficam a cerca de $100 \mathrm{~nm}$ de distância da superfície dentária, que também possui carga negativa determinada pelo grupo fosfato da hidroxiapatita. Essa distância pode ser vencida pelos microrganismos por meio das adesinas bacterianas (antígeno I/II de $S$. mutans) que se ligam a receptores especiais localizados nos constituintes salivares da película adquirida e pela síntese de polissacarídeos extracelulares (glucanos) envolvidos na aderência às superfícies lisas dos dentes ${ }^{4}$. Então, a aderência de $S$. mutans pode ser bloqueada inibindo as suas enzimas glicosiltranferases ou bloqueando a ação de suas adesinas.

Os resultados obtidos permitiram concluir que o Acmo 56G falhou em inibir a aderência do $S$. mutans à superfície dos corpos de prova, uma vez que os valores encontrados tanto nas dosagens bioquímicas, quanto na microbiológica, foram semelhantes para os grupos tratado e controle. Em outro trabalho Canettieri $^{2}$ (2001) utilizou o vidro como corpo de prova e concluiu que as placas bacterianas formadas in vitro na presença do Acmo $56 \mathrm{G}$ apresentavam menor conteúdo glicídico. A resina composta, mesmo após polimento, pode oferecer ao $S$. mutans uma superfície com micro-fissuras possibilitando sua fixação, semelhante ao que ocorre, in vivo, com as cáries oclusais ${ }^{4}$. Isso explicaria a semelhança quantitativa obtida na análise das placas formadas na ausência e presença do Acmo anti-S. mutans, sobre a resina composta.

Outro dado interessante foi a constatação que as placas bacterianas formadas na presença do Acmo sobre a resina composta esterilizada por radiação gama ou desinfetada por clorexidine não diferiram na dosagem protéica. Não se observou, também, contaminação em nenhum espécime através da análise microscópica do conteúdo do meio de cultura pela coloração de Gram. Essas observações são valiosas, pois sugerem que ao se avaliar a formação do biofilme bacteriano na superfície da resina composta, pode-se utilizar qualquer um dos métodos de descontaminação do corpo de prova, facilitando pesquisas futuras.

Os corpos de prova descontaminados pelos dois métodos adsorveram da mesma maneira o Acmo, uma vez que a análise do meio de cultura dos grupos controles e tratados, após a formação da placa bacteriana de 24 horas, não revelou diferença no que se refere ao teor protéico (dados não apresentados). Essa informação sugere que o Acmo ficou adsorvido sobre o material restaurador, mas não auxiliou no processo de formação de placa bacteriana de maneira significativa, pois não houve diferença estatística entre grupo controle e tratado. Este dado precisa ser levado em consideração, pois a imunoprofilaxia passiva com Acmo anti-S. mutans desenvolvidos em plantas transgênicas é uma nova terapia que em poucos anos estará disponível 
nos consultórios odontológicos ${ }^{7}$ e nenhum estudo abordando a presença de resina composta na cavidade bucal de pacientes foi realizado até o momento. Lehner et al. ${ }^{6}$ (1985) aplicaram topicamente um Acmo anti-S. mutans na superfície dos dentes de macacos. No grupo tratado a imunização passiva resultou na diminuição da colonização por $S$. mutans e preveniu o desenvolvimento de cáries por um período maior de um ano, comparativamente com a recolonização após 2-4 semanas do grupo controle. A longa duração da proteção na colonização bacteriana foi explicada pelos autores numa hipótese, segundo a qual os Acmo deveriam aderir à película adquirida na superfície dentária, ligando logo após, de maneira especifica, com $S$. mutans. A bactéria opsonizada seria, então, removida por neutrófilos gengivais e pelo sistema complemento e o nicho ecológico de $S$. mutans seria preenchido por outro microrganismo. Nosso trabalho sugere que o Acmo testado se ligou a superfície do material odontológico, o que in vivo poderia ser um fator positivo de prevenção da cárie dentária.

\section{Conclusões}

O anticorpo monoclonal 56G não foi efetivo na prevenção da colonização da superfície dos corpos de prova pelo Streptococcus mutans GS5. Os corpos de prova esterilizados por radiação gama não diferiram dos corpos de prova desinfetados com clorexidina quanto à capacidade de adsorver o anticorpo monoclonal. O anticorpo monoclonal 56G não apresentou atividade bactericida contra o Streptococcus mutans, cepa GS5.

\begin{abstract}
In this work, a 56G anti-Streptococcus mutans monoclonal antibody (Acmo) was analyzed, in vitro, about the effect in the attachment to and accumulation of S.mutans (strain GS5) on surface of specimen manufactured with Composite Resin TPH (Dentsply). Twenty samples were disinfected with gluconate chlohexidine or sterilized by gamma radiation and incubated in presence of sucrose and with an inoculum of S. mutans. One half of samples received the Acmo, another half was a control group. The dental plaques developed on the tablets of resin of the all groups were quantified and compared about total purport of protein and carbohydrate. The determination of the number of CFU/ml was analyzed. There was not difference among the disinfection with chlohexidine and the sterilization by gamma radiation, and the biofilm developed in the presence of Acmo did not differ of that formed in its absence, in relation of total carbohydrates, quantities of protein and microorganisms ( $p=0,577, p=0,705$ and $p=0,488$ respectively). The Acmo $56 G$ was not effective in the prevention of the colonization of $S$. mutans in surface of composite resin.
\end{abstract}

\title{
UNITERMS
}

Streptococcus mutans; antibody; composite resin.

\section{REFERÊNCIAS}

1. Ackermans F. Anti-IgG antibodies in rheumatic diseases cross-react whith Streptococcus mutans SR antigen. Clin Exp Immunol 1991 Aug.; 85(2):265-9.

2. Canettieri, ACV. Papel dos anticorpos monoclonais anti-Streptococcus mutans na formação de placa bacteriana em superfície vítrea e na identificação de $S$. mutans em placa dentária humana. [Dissertação] São José dos Campos: - Faculdade de Odontologia de São José dos Campos, Universidade Estadual Paulista; 2001.
3. Hajishengallis G, Koga T, Russell MW. Affinity and specificity of the interactions between Streptococcus mutans antigen I/II and salivary components. J Dent Res 1994 Sept.; 73(9):1493-9.

4. Jorge AOC, Microbiologia bucal. São Paulo: Editora Santos; 1988.

5. Kretchetoff FY. Produção de anticorpos monoclonais anti-Streptococcus mutans.. [Dissertação] - Faculdade de Odontologia de São José dos Campos, Universidade Estadual Paulista; 2001. 
6. Lehner T, Caldwell J, Smith R. Local passive immunization by monoclonal antibodies against streptococcal antigen $\mathrm{I} / \mathrm{II}$ in prevention of dental caries. Infect Immun 1985 Dec.; 50(3):796-810.

7. Ma JKC. Characterization of a recombinant plant monoclonal secretory and preventive immunotherapy in humans. Nat Med 1998 May.; 4(5):601-6.

8. McGhee JR, Michalek SM. Immunobiology of dental caries: microbiol aspects and local immunity. Ann Rev Microbiol 1981; 35:595-638.

9. Nisengard RJ, Newman MG. Microbiologia oral e imunologia. Rio de Janeiro: Editora Guanabara Koogan; 1997.
10. Pons A. A method for the simultaneous determination of total carbohydrate and glycerol in biological samples with anthrone reagent. J Biochen Biophys Methods 1981Mar.; 4(3):227-31.

11. Todryk SM. Induction of immune responses to functional determinants of a cell surface streptococcal antigen. Immunology 1996 Jan.; 87(1):55-63.

Recebido em: 13/04/07 Aprovado em: 15/08/07

Endereço para contato: Fabio José Condino Fujarra e-mail: fujarra@uol.com.br

Rua Prof. José Antonio Coutinho Condino, 682 - Jardim América São José dos Campos - CEP: 12235-360 - Tel: (12) 3933-8245 